\title{
Social correlates of sexual risk behaviors among urban men who have sex with men in Kolkata, India
}

\author{
Soumya Sarkar ${ }^{1}$, Subhasis Bhandari ${ }^{2}$, Pinaki Sensarma ${ }^{3}$
}

${ }^{1}$ Surveillance Medical officer, National Polio Surveillance Project, WHO, India. ${ }^{2}$ Public Health Consultant, Kolkata, India. ${ }^{3}$ State Reproductive Maternal Neonatal Child Health and Adolescent (RMNCH-A) Consultant, National Rural Health Mission, Assam, India.

\section{Abstract}

The factors defining the vulnerability of men who have sex with men (MSM) population are multiple and follow a complex social pattern culminating to their risk for human immunodeficiency virus (HIV) transmission. Even though the vulnerability of this population has been previously reported, prevention efforts are poor, may be due to the lack of understanding of the nature of sexual behavior in its social context. The main aim of this research was to study the social factors that are correlated with sexual risk behavior among the urban MSM population living in Kolkata. A community-based cross-sectional survey was conducted in the Kolkata Metropolitan Area using a pre-structured interview guide. Data obtained from 126 beneficiaries of the NGO networks representing the MSMs of the area, were analyzed. Prevalence of sexually transmitted infections (STI) among the MSMs during a recall period of last six months was used as a marker of sexual risk. Multiple logistic regression analyses were done to estimate and test associations between STI and social variables. The prevalence of STI among the respondents was $60.3 \%$ (95\% confidence interval (CI): 51.2-68.9). Inconsistent condom use (OR:11.98; 95\%CI: 4.03-35.59), low self -esteem (Rosenberg scale) (OR:4.18; 95\%CI: 1.48-11.82), substance abuse during sexual activity (OR:4.94; 95\%CI: 1.30-18.82), and adverse reactions when coming out (OR:4.91; 95\%CI: 1.63-14.77) were significantly associated with STI prevalence. For HIV risk reduction among the MSM population, intervention efforts should address the potential social stressors and adverse life events in addition to condom promotion.

Keywords: Sexual behavior, MSM, Homosexuality, STI, India.

\section{Introduction}

Nearly $10 \%$ of human immunodeficiency virus (HIV) infections have been attributed to sexual intercourse between men worldwide. ${ }^{1}$ Although, men having sex with men (MSM) have been the focus of attention for HIV intervention program in many countries since mid-80s, India has acknowledged the presence of MSM in the country only in the third phase of its National AIDS Control Programme (NACP-III, 2007-2012). ${ }^{2}$ Condoms are infrequently used during anal sex in the country, thereby increasing the risk of HIV transmission. ${ }^{3}$ It has been estimated that the MSM are 17.6 times more likely to acquire HIV infection compared to the general adult population in the country. ${ }^{4}$ World Health Organization has expressed deep concerns on the issue of multiple sex partners of MSM population and acknowledged the risk of the MSMs acting as a bridge population for HIV transmission to general population in the Asia Pacific region. $^{5}$

The biological vulnerability of these MSM for HIV transmission stems from their homosexual ano-receptive or ano-insertive or both receptive and insertive sex practice. ${ }^{6}$ Around 11 to $46 \%$ MSMs in India practice heterosexual relationships. ${ }^{7-9}$ Commercial sex work, which is mostly clandestine, is associated with two fold high risk of contracting HIV infection. ${ }^{9}$ Power imbalance between the provider and the purchaser of commercial sex coupled with intimate partner violence has constraining

\section{Practice Points}

- Unsafe sex among the men who have sex with men (MSM) is a significant public health problem in India.

- The susceptibility of MSM population follows a complex social pattern culminating to their risk for HIV transmission.

- Disclosure of MSM identity is not only taken adversely in the community but also punished under Indian Penal Code.

- Inconsistent condom use, low self esteem, substance abuse during sexual activity and adverse reactions faced during disclosure of sexual identity are the factors mainly associated with the risk of sexually transmitted infections including HIV.

- For HIV risk reduction among the MSM population, there is a need to develop appropriate and culturally relevant public health interventions to address the potential social stressors and adverse life events in addition to condom promotion.

effects on the space for negotiating safe sex. ${ }^{10,11}$ Criminalization and social marginalization of MSM activity further precipitate risk taking behavior,

Correspondence: Dr. Subhasis Bhandari, Public Health Consultant (Free-Lance), Bhandari House, Kolkata, India. Email: subhasisbhandari@gmail.com. 
making them more vulnerable to sexually transmitted infections (STI) including HIV., ${ }^{6,12}$ The social dimensions of the problem is comprised of ingrained societal homophobia, emotional and social rejection from the family and society, lack of safe space to engage in discourse on sexual health matters, the legal disapproval of the same sex practices and physical and sexual violence imparted on the MSM in a predominantly anti-gay society. ${ }^{11,14}$ Social oppression of gay men characterized by withdrawal of social support and prejudice against homosexuality creates considerable distress, giving rise to shame, secrecy and guilt, and adverse reactions during the coming out process, bring about depression, substance abuse and sexual risk behaviour. ${ }^{15}$ MSMs who reveal their sexual identities quite early are subjected to more violence associated with assault perpetrated by strangers, family members and peers. ${ }^{16}$ Such victimization, verbal and sexual abuse and harassment for the sexual minority youth manifest chronic stress associated with school-related problems, running away from home, conflict with law, substance abuse, prostitution and suicide. Some people may get psychosocial support from within the peer group or in accepting familial environment. Those who do not get this support are in a chronic conflict situation where they struggle for a sense of identity which confirms to their inner feelings and desires. ${ }^{17,18}$

The factors defining vulnerability of the MSM population are multiple and follow a complex social pattern culminating into their risk for HIV transmission. Even though the vulnerability has been realized for a long time, prevention efforts are poor, mostly due to the lack of understanding of the nature of the problem in its social context. This study aims to identify the social factors that are associated with sexual risk behaviors among an urban MSM population living in Kolkata city.

\section{Materials and Methods}

A cross-sectional survey was conducted during the three month period from June 10 to September 9, 2011. Criminalization and stigmatization have made MSMs a difficult population to study in India. They do not disclose their sexual identity but access their own peer network for their needs. The beneficiaries of the NGO networks of 'Manas Bangla' and 'Solidarity and Action Against The HIV Infection in India' (SAATHII), working for STD/HIV Intervention Programme under West Bengal State AIDS Prevention and Control Society, representative of the network of MSMs of the area, were selected for convenience sampling.

Sample size was estimated to be 126 at $95 \%$ confidence interval (CI) using Epi-info 3.4.3 StatCalc (Centers for Disease Control and Prevention, Atlanta, USA) considering an estimated STD prevalence of $9.92 \%$, based on the Needs Assessment study, in the sampling frame of 1400 MSM members of the mentioned peer network of NGOs in the area. ${ }^{19}$ Male individuals having either or both insertive and receptive anal sex with other male individuals, irrespective of the fact whether or not they have sex with opposite sex were included as MSM in this study. In order to ensure voluntary participation, care was taken to only include MSMs over 18 years of age.

\section{Ethical considerations}

The study was approved by the Technical Advisory Committee and the Institute Ethics Committee of the Sree Chitra Tirunal Institute for Medical Sciences and Technology, Thiruvananthapuram which was overseeing the research project. Written informed consent was formally obtained from each and every respondent who agreed to participate after being explained the nature and the objectives of the study. Participant confidentiality was respected during and after the study.

\section{Data collection}

A pre-structured interview guide along with a formal informed consent form was used to collect data. The interviews were conducted at the 'Drop in Centres' (DIC) located in the Kolkata Metropolitan Area including Dumdum, Kadapara, Kasba and Ballygunge DIC of Manas Bangla Project and Kadapara DIC of SAATHII. We conducted 25 interviews each in the first four centers and 26 interviews in the last centre as mentioned above to complete the required sample size of 126. Every alternate adult MSM attending the DIC was chosen for inclusion in the study till the required number was achieved. There was no refusal and all selected individuals had agreed to participate in the study.

Sexual transmission is the most common route for acquiring HIV in India. ${ }^{20}$ Most respondents were not aware of their HIV status and testing for HIV was not done. Instead, occurrence of STI within a recall period of last six months was considered as the proxy marker for the risk of HIV transmission. Self-reports on inconsistent condom use and multi partner sex were also collected as the other markers for high risk behavior. Data on age, highest level of education, income in Indian National Rupees (INR), living arrangement (dichotomized to living alone or with male partner and living with family including wife if married), selfreported predominant sexual identity of the respondent, marital status, age of sexual debut, substance abuse (alcohol and cannabis) during sexual activity, different forms of adverse reactions or rejection from peer and family and social circle during the coming out process i.e. voluntary disclosure of sexuality, partner violence, forced sex in public spheres and sexual assault, participation in commercial sex networks, participation in clandestine sex, sex with multiple partners (same or opposite sex) or single partner (male), pattern of consistent condom use dichotomized into consistent (i.e. always) and inconsistent (i.e. often, sometimes, or never) condom use among all sexual partners during the past one month and history of STI symptoms in the past six months among the respondents were collected.

Treatment cards of all the respondents available at the STI clinics attached to these DICs were used to record the sexual morbidity in the past six months. A validated scale called 'Rosenberg self esteem scale' was used to estimate self esteem with a cutoff value of 20 , below 
which self esteem was considered low and vice-versa. This scale, developed by Morris Rosenberg in 1965, is a ten item Likert scale. ${ }^{21}$ Each item was answered on a four point scale including strongly agree, agree, disagree and strongly disagree. Self reported presence of multiple sex partners of either same or opposite sex, inconsistent condom use among all sexual partners and history of STI symptoms among the respondents were used as binary outcome variables.

\section{Data entry, storage and statistical analysis}

All data collected were cleaned for any error or outliers which were then used for statistical analysis using SPSS version 17.0 for Windows (SPSS Inc, Chicago, USA). Frequencies (with percentage) were calculated for all the binary variables. Bivariate analyses were done and odds ratios (OR) with 95\% confidence intervals (CI) were calculated. Chi-square tests and Fisher's exact tests were used to find out the statistically significant associations during bivariate analysis. Finally a multivariable logistic regression analyses with history of STI symptoms among the respondents as the binary outcome variable was done to construct a model defining the predictors of sexual risk behaviors among the MSM. All the factors which were found significant during the bivariate analysis were included as the independent variables to construct the multivariable model. A p-value of less than 0.05 was considered to be statistically significant for all analyses.

\section{Results}

Data obtained from all the 126 consenting respondents were analyzed. None were reported to be hijra or male to female transgender. Among the MSM, 31.7\% respondents belonged to the age group less than 21 years, the legal age for marriage for males in the country. Only $35.7 \%$ of the respondents had education beyond the primary level. Most of the respondents $(65.9 \%)$ were either living alone or with their male partner. Notably, $84.9 \%$ respondents had their first sexual act before attaining 18 years of age, the legal age for giving any valid consent. Around 70.6\% MSM participated in commercial sex work. Almost all of them had some income except only $3.2 \%$ who were students. These MSM had an average income of INR 5000 (the equivalent of US\$ 89.69 per month based on an exchange rate of US $\$ 1=$ INR 55.75 ) and $46.8 \%$ respondents had income more than this average.

Among all respondents, $17.5 \%$ were married to women. Partner violence was faced by $54 \%$, forced sex or sexual assault by $59.5 \%$, and different forms of adverse reactions or rejection from peer, family and social circle during the coming out process by $61.9 \%$ respondents. Around $56.3 \%$ respondents had expressed very low self esteem. Substance abuse (alcohol and cannabis) during the sexual act was reported by $76.9 \%$. Sex with multiple partners was reported by $84.1 \%$ MSMs and $65.1 \%$ reported that they did not use condoms consistently during their sexual activities. The socioeconomic profile and risk behaviors of the study population are given in Table 1.
The symptoms of STI in the past six months was reported by $60.3 \% \quad(95 \%$ CI: $51.2 \%-68.9 \%)$ respondents. The symptoms were mainly anal discharge (28.6\%), anal ulcer $(37.3 \%)$, genital discharge $(37.5 \%)$, genital ulcer $(13.5 \%)$, groin swelling $(5.6 \%)$ and lower abdominal pain $(5.6 \%)$, and there were multiple symptoms in many cases. The results of bivariate analysis of all the independent variables with the markers for high risk sexual behavior among the MSM, including sex with multiple partners, inconsistent consistent condom use among all sexual partners and history of STI symptoms among the respondents during the past six months as the outcome variable are given in table 2. Factors including primary level of education, income less than INR 5000, living alone or with male partner, sexual debut before attaining the adult age of 18 years, substance abuse during sexual activity, adverse reactions during the coming out process, partner violence, forced sex in public spheres and sexual assault, participation in commercial sex networks, participation in clandestine sex and low self esteem significantly affected the outcome variables.

The results of multivariable analysis are given in table 3 . In this model, inconsistent condom use, low self esteem, substance abuse during sexual activity, and the different forms of adverse reactions during the coming out process were found to have significantly higher odds of STI symptoms.

\section{Discussion}

The occurrence of symptoms of STI within a recall period of six months has been reported by $60.3 \%(95 \%$ CI: 51.2-68.9) respondents. Setia et al have reported point prevalence of STI of $20 \%$ among MSMs in Mumbai, India. ${ }^{12}$ Again Deuba et al have reported annual prevalence of symptoms of STI to be $35.3 \%$ among the MSMs in Kathmandu, Nepal. ${ }^{22}$ The self reported prevalence of STI in the study population over a period of six months seems to be quite high making them more vulnerable for HIV transmission. Moreover this also indicates their high risk sexual behavior.

The respondents who are not using condom consistently during their sexual acts have twelve times higher odds of contracting STI. Koblin et al from US have also reported unprotected anal intercourse to be an independent risk for HIV acquisition. ${ }^{23}$ Inconsistent condom use with regular partner or casual male and female partner is itself a marker of high risk sexual activity. Deuba et al. have considered inconsistent condom use as the outcome indicator for high risk sexual behavior among MSMs. ${ }^{24}$ Consistently low condom use indicates a higher risk of HIV transmission and also spill over into the general population. ${ }^{8}$ Around $65.8 \%$ respondent are seen to stay alone or with a male partner and such living arrangement confers a higher risk of having multi partner sex, inconsistent condom use and higher risk of acquiring STI and HIV. Living with a male partner is also associated with increased partner violence and high risk behavior including poor condom use. Leaving home to live with male partner indicates lack of family support as well as other social

South East Asia Journal of Public Health 2014;4(1):17-24 
Table 1: Socioeconomic profile and self-reported risk behaviors

\begin{tabular}{|c|c|c|c|c|c|c|}
\hline \multirow[t]{2}{*}{ Variables } & \multicolumn{2}{|c|}{ Sex partner } & \multicolumn{2}{|c|}{$\begin{array}{l}\text { Self-reported pattern of } \\
\text { condom use }\end{array}$} & \multicolumn{2}{|c|}{$\begin{array}{l}\text { History of STI during } \\
\text { past } 6 \text { months }\end{array}$} \\
\hline & Multiple* & Single & $\begin{array}{c}\text { Inconsis- } \\
\text { tent }\end{array}$ & Consistent & Present & Absent \\
\hline \multicolumn{7}{|l|}{ Age Group } \\
\hline$<21$ years & $33(82.5 \%)$ & $7(17.5 \%)$ & $27(67.5 \%)$ & $13(32.5 \%)$ & $29(72.5 \%)$ & $11(27.5 \%)$ \\
\hline$\geq 21$ years & $73(84.9 \%)$ & $13(15.1 \%)$ & $55(64 \%)$ & $31(36 \%)$ & $47(54.7 \%)$ & $39(45.3 \%)$ \\
\hline \multicolumn{7}{|l|}{ Education } \\
\hline sprimary education & $72(88.9 \%)$ & $9(11.1 \%)$ & $59(72.8 \%)$ & $22(27.2 \%)$ & $56(69.1 \%)$ & $25(30.9 \%)$ \\
\hline$>$ primary education & $34(75.6 \%)$ & $11(24.4 \%)$ & $23(51.1 \%)$ & $22(48.9 \%)$ & $20(44.4 \%)$ & $25(55.6 \%)$ \\
\hline \multicolumn{7}{|l|}{ Average monthly income } \\
\hline$<5000$ INR & $59(88.1 \%)$ & $8(11.9 \%)$ & $44(65.7 \%)$ & $23(34.3 \%)$ & $46(68.7 \%)$ & $21(31.2 \%)$ \\
\hline$\geq 5000$ INR & $47(79.7 \%)$ & $12(20.3 \%)$ & $38(64.4 \%)$ & $21(35.6 \%)$ & $30(50.8 \%)$ & $29(49.2 \%)$ \\
\hline \multicolumn{7}{|l|}{ Living arrangement } \\
\hline Living alone or with male partner & $76(91.6 \%)$ & $7(8.4 \%)$ & $59(71.1 \%)$ & $24(28.9 \%)$ & $57(68.7 \%)$ & $26(31.3 \%)$ \\
\hline Living with family & $30(69.8 \%)$ & $13(30.2 \%)$ & $23(53.5 \%)$ & $20(46.5 \%)$ & $19(44.2 \%)$ & $24(55.8 \%)$ \\
\hline \multicolumn{7}{|l|}{ Self-reported sexual identity } \\
\hline Receptive & $100(84 \%)$ & $19(16 \%)$ & $79(66.4 \%)$ & $40(33.6 \%)$ & $73(61.3 \%)$ & $46(38.7 \%)$ \\
\hline Penetrative & $6(85.7 \%)$ & $1(14.3 \%)$ & $3(42.9 \%)$ & $4(57.1 \%)$ & $3(42.9 \%)$ & $4(57.1 \%)$ \\
\hline \multicolumn{7}{|l|}{ Marital status } \\
\hline Unmarried to women & $87(83.7 \%)$ & $17(16.3 \%)$ & $67(64.4 \%)$ & $37(35.6 \%)$ & $62(59.6 \%)$ & $42(40.4 \%)$ \\
\hline Married to women & $19(86.4 \%)$ & $3(13.6 \%)$ & $15(68.2 \%)$ & $7(31.8 \%)$ & $14(63.6 \%)$ & $8(36.4 \%)$ \\
\hline \multicolumn{7}{|l|}{ Age of sexual debut } \\
\hline$<18$ years & $14(73.7 \%)$ & $5(26.3 \%)$ & $9(47.4 \%)$ & $10(52.6 \%)$ & $7(36.8 \%)$ & $12(63.2 \%)$ \\
\hline$\geq 18$ years & $92(86 \%)$ & $15(14 \%)$ & $73(68.2 \%)$ & $34(31.8 \%)$ & $69(64.5 \%)$ & $38(35.5 \%)$ \\
\hline \multicolumn{7}{|l|}{ Substance abuse during sexual activity } \\
\hline Yes & $89(91.8 \%)$ & $8(8.2 \%)$ & $73(75.3 \%)$ & $24(24.7 \%)$ & $69(71.1 \%)$ & $28(28.9 \%)$ \\
\hline No & $17(58.6 \%)$ & $12(41.4 \%)$ & $9(31 \%)$ & $20(69 \%)$ & $7(24.1 \%)$ & $22(75.9 \%)$ \\
\hline \multicolumn{7}{|c|}{ Adverse reactions during the coming out } \\
\hline Yes & $70(89.7 \%)$ & $8(10.3 \%)$ & $56(71.8 \%)$ & $22(22.2 \%)$ & $56(71.8 \%)$ & $22(28.2 \%)$ \\
\hline No & $36(75 \%)$ & $12(25 \%)$ & $26(54.2 \%)$ & $22(45.8 \%)$ & $20(41.7 \%)$ & $28(58.3 \%)$ \\
\hline \multicolumn{7}{|l|}{ Partner violence } \\
\hline Yes & $63(92.6 \%)$ & $5(7.4 \%)$ & $50(73.5 \%)$ & $18(26.5 \%)$ & $47(69.1 \%)$ & $21(31.9 \%)$ \\
\hline No & $43(74.1 \%)$ & $15(25.9 \%)$ & $32(55.2 \%)$ & $26(44.8 \%)$ & $29(50 \%)$ & $29(50 \%)$ \\
\hline \multicolumn{7}{|l|}{ History of sexual assault } \\
\hline Yes & $70(93.3 \%)$ & $5(6.7 \%)$ & $60(80 \%)$ & $15(20 \%)$ & $52(69.3 \%)$ & $23(30.7 \%)$ \\
\hline No & $36(70.6 \%)$ & $15(29.4 \%)$ & $22(43.1 \%)$ & $29(56.9 \%)$ & $24(47.1 \%)$ & $27(52.9 \%)$ \\
\hline \multicolumn{7}{|l|}{ Participation in commercial sex } \\
\hline Yes & $84(94.4 \%)$ & $5(5.6 \%)$ & $66(74.2 \%)$ & $23(25.8 \%)$ & $61(68.5 \%)$ & $28(31.5 \%)$ \\
\hline No & $22(59.5 \%)$ & $15(40.5 \%)$ & $16(43.2 \%)$ & $21(56.8 \%)$ & $15(40.5 \%)$ & $22(59.5 \%)$ \\
\hline \multicolumn{7}{|l|}{ Participation in clandestine sex } \\
\hline Yes & $78(94 \%)$ & $5(6 \%)$ & $61(73.5 \%)$ & $22(26.5 \%)$ & $56(67.5 \%)$ & $27(32.5 \%)$ \\
\hline No & $28(65.1 \%)$ & $15(34.9 \%)$ & $21(48.8 \%)$ & $22(51.2 \%)$ & $20(46.5 \%)$ & $23(53.5 \%)$ \\
\hline \multicolumn{7}{|l|}{ Self esteem (Rosenberg scale) } \\
\hline Low & $65(91.5 \%)$ & $6(8.5 \%)$ & $59(83.1 \%)$ & $12(16.9 \%)$ & $58(81.7 \%)$ & $13(18.3 \%)$ \\
\hline High & $41(74.5 \%)$ & $14(25.5 \%)$ & $23(41.8 \%)$ & $32(51.2 \%)$ & $18(32.7 \%)$ & $37(67.3 \%)$ \\
\hline
\end{tabular}

* Self reported presence of multiple sex partners of either same or opposite sex

support that contributes to risk taking behaviour. Pierce et al. have has reported such higher risk behavior among the African American MSMs living with their male partners. ${ }^{24}$

Substance abuse prior to the sexual activity has five times higher odds of reporting to have STI symptoms in the past six months. Koblin et al. have also reported that substance abuse, alcohol and cannabis, is associated with high risk sexual behavior among MSMs. ${ }^{17}$ Substance abuse is found to be high among MSM and is associated with multi-partner sex and inconsistent condom use. ${ }^{25}$ Consumption of alcohol or any other psychedelic is associated with higher episodes of unprotected anal intercourse and higher rates of condom failure. Also, syndemics of substance abuse contains various social and psychological stressors like psychosocial health problems, depression, and intimate partner violence. Combinations of these risk factors are the precipitating events for an individual indulging in higher risk of unprotected anal intercourse with multiple sex partners. ${ }^{26,27}$ Youth resorts to substance use for reducing their pain, external conflict and internal inhibitions of same sex relationship. ${ }^{27}$

Any adverse reactions during the coming out process

South East Asia Journal of Public Health 2014;4(1):17-24 
Table 2: Factors associated with self-reported high risk behavior: Results of bi-variate analysis

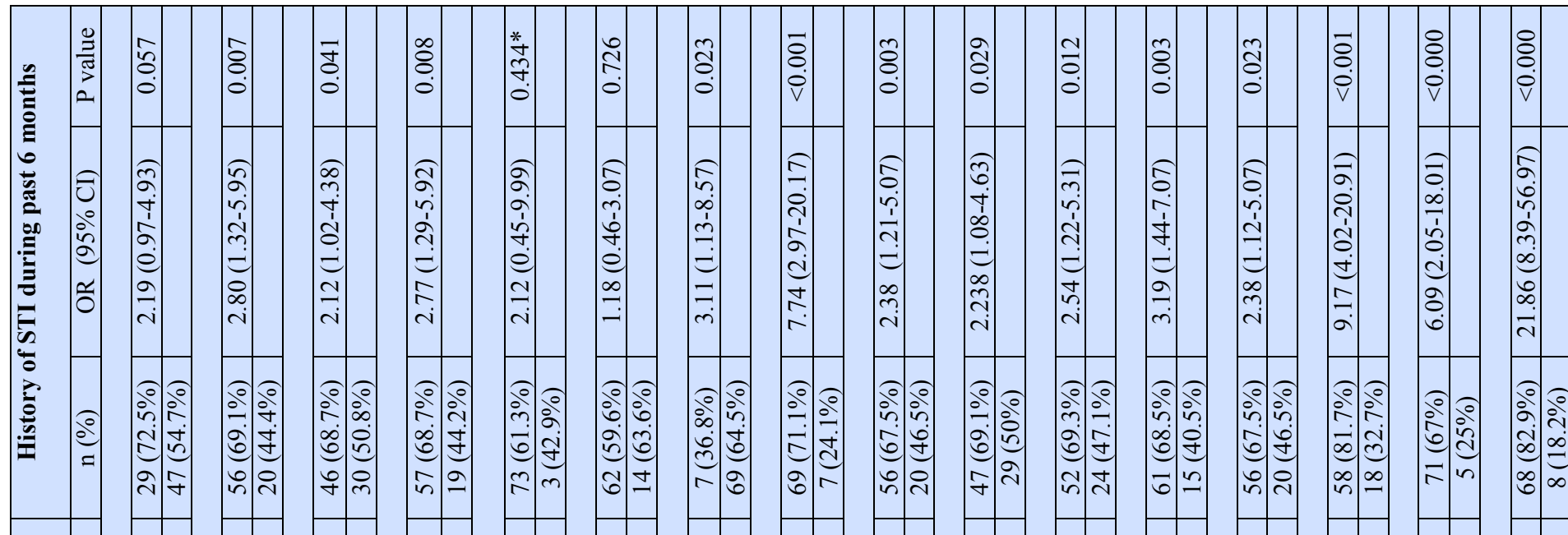

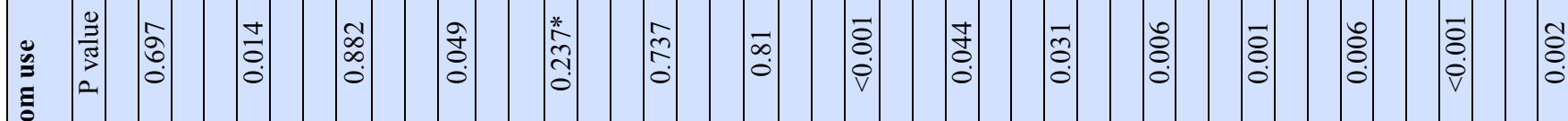

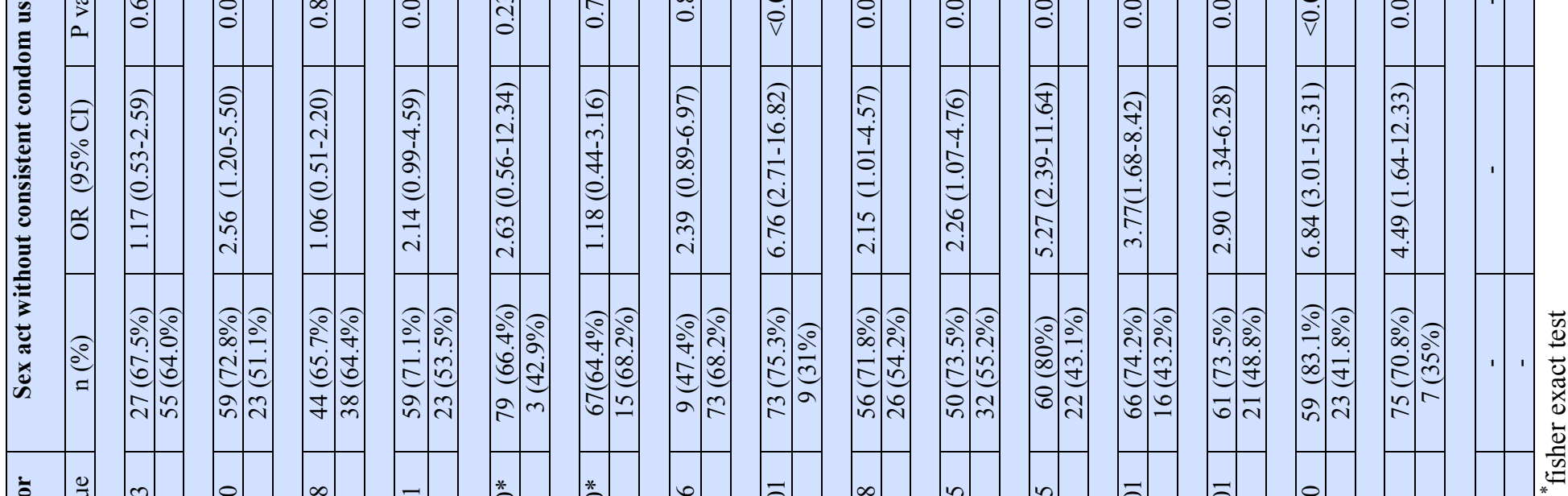

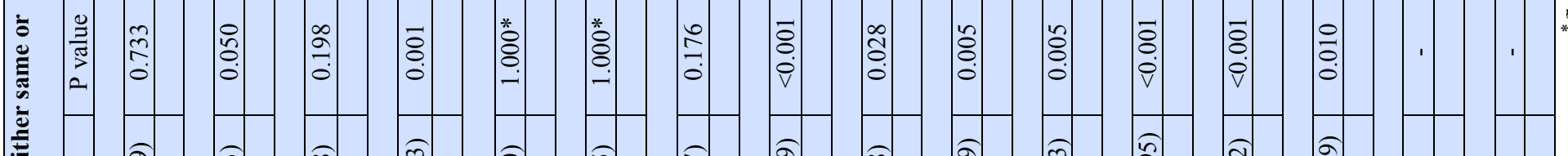

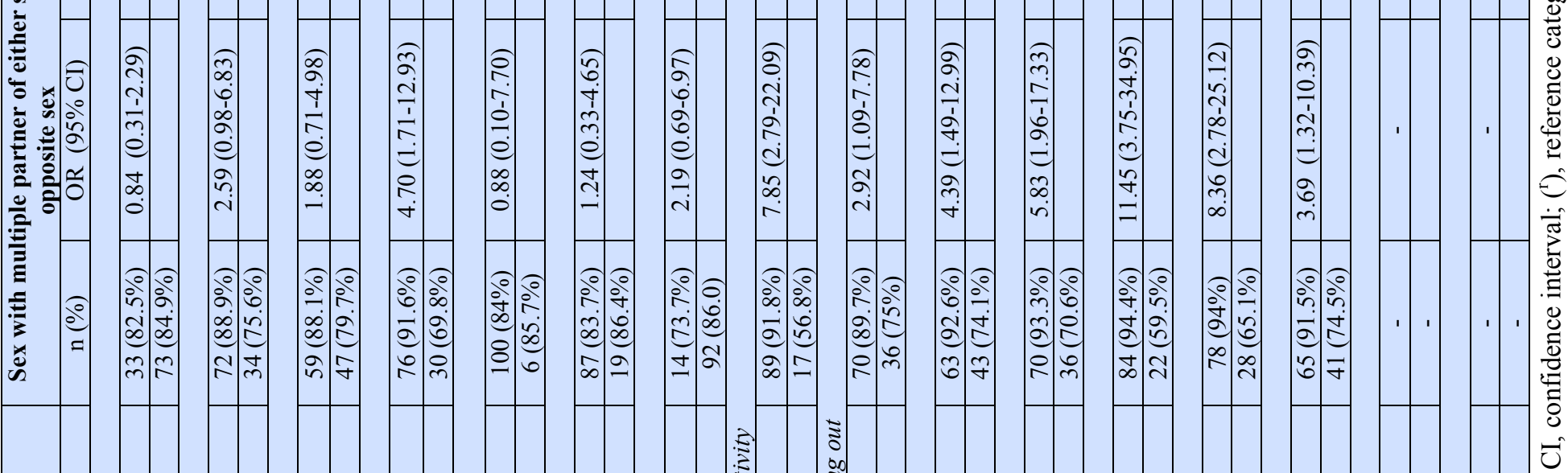


Table 3: Factors associated with history of STI during past 6 months: Results of multivariable analysis ${ }^{\mathrm{a}}$

\begin{tabular}{|c|c|c|c|}
\hline Variables & n $(\%)$ & $\begin{array}{c}\text { Adjusted OR } \\
(95 \% \text { CI })\end{array}$ & p-value \\
\hline \multicolumn{4}{|l|}{ Pattern of condom use } \\
\hline Inconsistent & $68(82.9)$ & $11.98(4.03-35.59)$ & $<0.001$ \\
\hline Consistent $^{r}$ & $8(18.2)$ & & \\
\hline \multicolumn{4}{|l|}{ Self-esteem (Rosenberg scale) } \\
\hline Low & $58(81.7)$ & $4.18(1.48-11.82)$ & 0.007 \\
\hline $\operatorname{High}^{r}$ & $18(32.7)$ & & \\
\hline \multicolumn{4}{|c|}{ Substance abuse during sexual activity } \\
\hline Yes & $69(71.1)$ & $4.94(1.30-18.82)$ & 0.019 \\
\hline $\mathrm{No}^{r}$ & $7(24.1)$ & & \\
\hline \multicolumn{4}{|c|}{ Adverse reactions during the coming out } \\
\hline Yes & $56(67.5)$ & $4.91(1.63-14.77)$ & 0.005 \\
\hline $\mathrm{No}^{r}$ & $20(46.5)$ & & \\
\hline
\end{tabular}

Abbreviations: OR, odds ratio; CI, confidence interval; $\left({ }^{\mathrm{r}}\right)$, reference category.

${ }^{a}$ Dependent variable: history of STI during past 6 months, other variables considered in this model and not found to be significant were education, average monthly income, living arrangement, age of sexual debut, partner violence, history of sexual assault, participation in commercial sex, participation in clandestine sex, and sex with multiple partner of either same or opposite sex

Note: Model Nagelkerke $\mathrm{R}^{2}$ : 0.614 , chi-square for the model: 76.127

also have five times higher odds of acquisition of STI. Coming out process is a major life event where people begin to understand their sexual identity. Generally the coming out process is associated with structural violence which may affect the sexual risk taking behavior. Moreover, discovering and adapting to a non normative sexual identity, particularly without the psychological resilience and coping resource of maturity makes them more vulnerable to gay related stressors. ${ }^{28}$ Internalized homophobia, extreme stigmatization and criminalization of MSM activity limit the same sex sexual discourse in the public sphere. As a reason most of the MSM sexual activities are conducted in clandestine manner. This invisibility by itself is a challenge to preventive effort. Condom negotiation is also difficult, if not impossible, in clandestine sexual encounters taking place in public places, making MSM more vulnerable to sexual violence and assault, thereby adding up to the life stress in this marginalized population group. ${ }^{28}$

Living with MSM identity in Indian homophobic societal structure marginalizes a person. Discovering ones sexual identity and disclosure to the family is generally the beginning of a stigmatized existence which is associated with cultural and familial stressors. Pervasive antigay sentiments mean ostracism from family and friends. Stigma of non normative sexual identity by itself is a predictor of high risk. Structural exclusion from the social sphere produces a poor quality of life aggravating the scenario, resulting in low self esteem. Among other social and psychological constructs of antigay stressors which give rise to low self esteem may include self sense of deviance, loss of social support from peer group, vulnerability to antigay harassment and violence. ${ }^{29,30}$ This leads to depression, anger and heightened sense of vulnerability and low self esteem. Feeling of low self esteem as measured by the respondents has four times higher odds of high risk sexual behavior culminating in acquiring STI. MSM activity is associated with stigma which contributes to a negative self image. All these contribute to their increased risk behavior including unprotected anal intercourse. ${ }^{9}$ Poverty and lack of alternate livelihood coupled with low self esteem force the MSMs to work as sex workers. Participation in commercial sex work is strongly linked with a plethora of risks including multipartner sex, inability to negotiate condom use, limited access to health care service and proneness to sexual violence, and substance abuse. The double stigma of MSM identity and sex worker further generates low self esteem and depression, thereby creating a vicious cycle. Lack of legislative protection against abuse and violence is another factor contributing to the syndemics of higher HIV risk. ${ }^{9,12,28}$

\section{Limitations}

The outcomes of interest in the present study, mainly the sexual behavior, are based on patients' self-reports which may have been subject to social desirability bias. Specifically the high rates of STI might be due to the recruitment sites being adjacent to STI clinics. Reliance on memory recall and a relatively small sample size with a large number of predictors being initially included in the stepwise model are other potential limitations of the study. A drawback of this stepwise procedure is that it can demonstrate a chance association as a significant one. However, the findings broadly agree with other studies among the MSMs.

\section{Conclusion}

Analysis of the societal correlates of the high risk sexual behavior of MSM appears to be complex one. Due to prevailing societal norms the disclosure of one's sexual identity is taken adversely in the community. This is further worsened by low self esteem. Societal violence, 
negative self image all contributes to low self esteem. Under these stressors, MSMs resort to substance abuse that leads to inconsistent condom use or wrong use of condom. For HIV risk reduction among MSM population, intervention efforts should address the social stressors and adverse life events in addition to condom promotion.

\section{Acknowledgement}

We are grateful to Dr. Mala Ramanathan, for her guidance and technical comments throughout the research work. We are thankful to the West Bengal State AIDS Prevention and Control Society for providing the permission to carry out the study in the selected areas. We sincerely appreciate the help and logistic supports provided by the staffs of the NGO networks of 'Manas Bangla' and SAATHII and acknowledge their full cooperation and assistance given for conduct of this study.

\section{References}

1. UNAIDS, World AIDS campaign 2001. http:// www.unaids.org/wac/2001 (accessed June 2014)

2. Asthana S, Oostvogels R. The social construction of male homosexuality in India: implications for HIV transmission and prevention. Soc Sci Med 2001;52:707-21.

3. Parker R, Khan S, Aggleton P. Conspicuous by their absence? MSM in developing countries: implication for HIV prevention. Crit Public Health 1998;8:329-46.

4. Baral S, Sifakis F, Cleghorn F, Beyrer C. Elevated risk for HIV infection among men who have sex with men in low- and middle-income countries 2000-2006: a systematic review. PLoS Med 2007; 4:1901-11

5. World Health Organization. HIV /AIDS in Asia and the Pacific region. New Delhi, Manila: WHO, 2001.

6. Stone E, Heagerty P, Vittinghoff E, Douglas JM $\mathrm{Jr}$, Koblin BA, Mayer $\mathrm{KH}$, et al. Correlates of condom failure in a sexually active cohort of men who have sex with men. J Acquir Immune Defic Syndrome Hum Retrovirol 1999;20:495501 .

7. Schneider JA, Saluja GS, Oruganti G, Dass S, TolentinoJ, Laumann EO, et al. HIV infection dynamics in rural Andhra Pradesh south India: a sexual-network analysis exploratory study. AIDS Care 2007;19:1171-6.

8. Brahmbhatt KR, Oza UN, Shah C. Socio-demographic profile, awareness regarding HIV/AIDS and self reported sexual behavior of men having sex with men in Ahmedabad, India. Int J Biol Med Res 2012; 3:2126-31.

9. Diaz RM, Ayala G, Bein E. Sexual risk as an outcome of social oppression: data from a probability sample of Latino gay men in three U.S. cities. Cultur Divers Ethnic Minority Psychol 2004;10:255-67.

10. Thomas B, Mimiaga MJ, Mayer KH, Johnson $\mathrm{CV}$, Menon S, Chandrasekharn V, et al. Unseen and unheard: predictors of sexual risk behaviourand HIV infection among men who have sex with men in Chennai, India. AIDS Educ Prev 2009;21:372-83.

11. Kaestle CE, Halpern CT, Miller WC, Ford CA. Young age at first sexual intercourse and sexually transmitted infections in adolescents and young adults. Am J Epidemiol 2005;161:774 -80 .

12. Setia MS, Brassard P, Jerajani HR, Bharat S, Gogate A, Kumta S, et al. Men who have sex with men in India: a systematic review of the literature. J LGBT Health Res 2008;4:51-70.

13. The Foundation for AIDS Research. MSM and the Global HIV/AIDS Epidemic: Assessing PEPFAR and Looking Forward. amfAR AIDS Res 2010; July Issue: 1-16.

14. AVERTing HIV/AIDS. Men Who Have sex with men (MSM). What makes men who have sex with men vulnerable to HIV/AIDS? http:// www.avert.org/msm.htm (accessed June 2014)

15. Gutierrez JP, McPherson S, Fakoya A, Matheou A, Bertozzi SM. Community-based prevention leads to an increase in condom use and a reduction in sexually transmitted infections (STIs) among men who have sex with men (MSM) and female sex workers (FSW): the Frontiers Prevention Project (FPP) evaluation results. BMC Public Health 2010;10:497.

16. Rosario M, Schrimshaw EW, Hunter J. A model of sexual risk behaviors among young gay and bisexual men: longitudinal associations of mental health, substance abuse, sexual abuse, and the coming-out process. AIDS Educ Prev 2006;18:444-60.

17. Koblin BA, Chesney MA, Husnik MJ, MS, Bozeman S, Celum CL, Buchbinder S, et al. High-risk behaviors among men who have sex with men in 6 US cities: baseline data from the EXPLORE Study. Am $J$ Public Health 2003;93:926-32.

18. World Health Organization. Treatment for sexually transmitted infections has a role in HIV prevention. http://www.who.int/mediacentre/ news/releases/2006/pr40/en/index.html (accessed June 2012)

19. West Bengal State AIDS Prevention and Control Society, Department of Health and Family Welfare, Government of West Bengal. Community Needs Assessment Report, Kolkata, 2003. 
20. National AIDS Control Organisation. NACO Annual Report 2010-11. New Delhi: Department of AIDS Control, National AIDS Control Organization, Ministry of Health and Family Welfare, Government of India, 2011.

21. Rosenberg M. Society and the adolescent selfimage, Revised ed., Middletown, CT, England: Wesleyan University Press 1989;347.

22. Deuba K, Karki DK, Srestha R, Aryal UR, Bhatta L, Rai KK. Risk of HIV Infection Among Men Having Sex With Men in Kathmandu Valley, Nepal. Asia-Pac J Public Health 2014;26(2):126-37.

23. Pierce SJ, Miller RL, Morales MM, Forney J. Identifying HIV prevention service needs of African American men who have sex with men: an application of spatial analysis techniques to service planning. J Public Health Manag Pract 2007;Jan: S72-9.

24. Koblin BA, Husnik MJ, Colfax G, Huang Y, Madison M. Mayer K. Risk factors for HIV infection among men who have sex with men. AIDS 2006;20:731-9.

25. Aynalem G, Smith L, Bernis C, Taylor M, Hawkins K, Kerndt P. Commercial sex venues: a closer look at their impact on the syphilis and HIV epidemics among men who have sex with men. Sex Transm Infect 2006;82:439-43.
26. Mustanski B, Garofalo R, Herrik A, Donenberg G. Psychosocial health problems increase risk for HIV among urban young men who have sex with men: preliminary evidence of a syndemic in need of attention. Ann Behav Med 2007;34:37-45.

27. Dudley MG, Rostosky SS, Korfhage BA, Zimmerman S. Correlates of high-risk sexual behavior among young men who have sex with men. AIDS Educ Prev 2004;16:328-40.

28. Thomas B, Mimiagia MJ, Senthil S, Swaminathan S, Safren SA, Mayer KH. HIV in Indian MSM: reasons for a concentrated epidemic \& strategies for prevention. Indian $J$ Med Res 2011;134: 920-9.

29. Houston E, McKirnan DJ, Intimate partner abuse among gay and bisexual men: risk correlates and health outcomes. $J$ Urban Health 2007;84:68190 .

30. Greenwood GL, Relf MV, Huang B, Pollack LM, Canchola JA, Catonia JA. Battering victimisation among a pobability based sample of men who have sex with men. Am $J$ Public Health 2002;92:1964-9. 